\title{
Ion-beam mixing induced by atomic and cluster bombardment in the electronic stopping-power regime
}

\author{
M. Beranger, P. Thevenard, R. Brenier, B. Canut, and S. M. M. Ramos \\ Département de Physique des Matériaux, Université Claude Bernard, Lyon I, 69622 Villeurbanne Cedex, France \\ A. Brunelle, S. Della Negra, and Y. Le Beyec \\ Institut de Physique Nucléaire, Orsay, 91406 Orsay Cedex, France \\ E. Balanzat \\ Centre Interdisciplinaire de Recherches avec les Ions Lourds, 14040 Caen Cedex, France \\ T. Tombrello \\ 200-36 California Institute of Technology, Pasadena, California 91125
}

(Received 31 July 1995)

\begin{abstract}
Single crystals of magnesium oxide containing nanoprecipitates of sodium were bombarded with swift ions $(\sim \mathrm{GeV}-\mathrm{Pb}, \mathrm{U})$ or cluster beams $\left(\sim 20 \mathrm{MeV}-\mathrm{C}_{60}\right)$ to study the phase change induced by electronic processes at high stopping power $(>10 \mathrm{keV} / \mathrm{nm})$. The sodium precipitates and the defect creation were characterized by optical absorption and transmission electron microscopy. The ion or cluster bombardment leads to an evolution of the Na precipitate concentration but the size distribution remains unchanged. The decrease in Na metallic concentration is attributed to mixing effects at the interfaces between $\mathrm{Na}$ clusters and $\mathrm{MgO}$. In addition, optical-absorption measurements show a broadening of the absorption band associated with electron plasma oscillations in Na clusters. This effect is due to a decrease of the electron mean free path, which could be induced by defect creation in the metal. All these results show an influence of high electronic stopping power in materials known to be very resistant to irradiation with weak ionizing projectiles. The dependence of these effects on electronic stopping power and on various solid-state parameters is discussed. [S01631829(96)07021-X]
\end{abstract}

\section{INTRODUCTION}

It has been known that the implantation of alkali ions in insulating materials like $\mathrm{LiF}$ or $\mathrm{MgO}$ can lead to the formation of metallic nanoprecipitates of the alkali metal after annealing. ${ }^{1,2}$ Irradiation with low-energy ions of these precipitates results in their elimination by nuclear collision processes. The modification of the precipitated metal is due to atomic mixing at the host matrix-precipitate interface. ${ }^{3}$

As far as inelastic scattering processes are concerned, it was long thought that energy deposition through electronic excitations could neither be responsible for defect creation in metals (because of their very high electron conductivity) nor in refractory oxides (because the atomic displacement energy of oxygen much exceeds the width of their electronic bandgap). ${ }^{4}$ Recent works nevertheless showed that for high electronic excitation levels, inelastic collision processes lead to significant damage in metals ${ }^{5,6}$ and in oxides. ${ }^{7,8}$ Therefore it could be expected that irradiation at high electronic stopping power of $\mathrm{MgO}$ crystals containing metal precipitates would induce some modification of the precipitated phase. Electronic energy losses exceeding $45 \mathrm{keV} / \mathrm{nm}$ are difficult to obtain in $\mathrm{MgO}$ by irradiation with swift monoatomic ions. To go beyond this limit, it is necessary to perform irradiations with cluster ions. The energy losses of clusters in matter are not known with accuracy; however recent work shows that the energy loss of a $\mathrm{C}_{60}$ molecule in the solid is approximately equal to the sum of the energy losses of each atom of the molecule. ${ }^{9}$ Electronic stopping powers up to $60 \mathrm{keV} / \mathrm{nm}$ can then be estimated for irradiations with clusters at an energy of about $20 \mathrm{MeV}$.

In this paper, we report on the effect of swift heavy ions (energy $\sim \mathrm{GeV}$ ) on $\mathrm{Na}$ precipitates embedded in a $\mathrm{MgO}$ matrix. Irradiations of such $\mathrm{MgO} / \mathrm{Na}$ systems by high-energy $\mathrm{C}_{60}$ cluster beams $(\sim 20 \mathrm{MeV})$ were also performed. In both cases, the electronic energy losses of the incident ions or molecules were orders of magnitude higher than the nuclear energy losses in the part of the crystal containing the precipitates.

\section{EXPERIMENTAL PROCEDURE}

High purity (99.99\%) $\mathrm{MgO}$ single crystals of (100) orientation were used. The thickness of the crystals was about 1 $\mathrm{mm}$ and their surfaces were cleaved and optically polished to remove cleavage steps. The samples were first implanted at room temperature with $150 \mathrm{keV} \mathrm{Na}^{+}$ions at a fluence of $10^{17}$ $\mathrm{Na} \mathrm{cm}{ }^{-2}$ using the $200 \mathrm{keV}$ implantor of the Département de Physique des Matériaux. The mean projected range was 185 $\mathrm{nm}$ and the longitudinal range straggling $50 \mathrm{~nm}$. The samples were then subjected to an isochronal annealing in air up to 800 or $1000{ }^{\circ} \mathrm{C}$ in order to induce precipitation of the metallic sodium.

The $\mathrm{MgO}$ crystals containing $\mathrm{Na}$ nanoprecipitates were further irradiated, either with swift heavy ions $(\mathrm{U}, \mathrm{Pb}, \mathrm{Sn}$, $\mathrm{Kr}$ ) at GANIL or with $\mathrm{C}_{60}^{+}$cluster beams at the Institut de 
TABLE I. Summary of the main experimental characteristics of the incident ions and clusters.

\begin{tabular}{lcccccccc}
\hline \hline Incident ion & $\mathrm{Pb}$ & $\mathrm{Sn}$ & $\mathrm{Sn}$ & $\mathrm{Kr}$ & $\mathrm{U}$ & $\mathrm{C}_{2}$ & $\mathrm{C}_{60}$ & $\mathrm{C}_{60}$ \\
\hline Energy $(\mathrm{MeV})$ & 944 & 1066 & 315 & 842 & 45 & 0.6 & 18 & 23 \\
Ion range $(\mu \mathrm{m})$ & 31 & 55 & 19 & 63.5 & 4.4 & 0.40 & 0.40 & 0.46 \\
$\begin{array}{l}\text { Electronic stopping } \\
\text { power in MgO (keV/nm) }\end{array}$ & 38 & 19 & 24 & 11 & 11 & 1.3 & 40 & 62 \\
$\begin{array}{l}\text { Nuclear stopping power } \\
\text { in MgO (keV/nm) }\end{array}$ & 0.07 & 0.014 & 0.04 & $7 \times 10^{-3}$ & 1.0 & 0.47 & 1.4 & 0.67 \\
\hline \hline
\end{tabular}

Physique Nucléaire d'Orsay. The characteristics of the ions (energy, range, electronic and nuclear energy losses) are reported in Table I.

Optical-absorption measurements were carried out either in situ at ISOC (GANIL) at 17 and $300 \mathrm{~K}$ during the irradiations with $\mathrm{Pb}, \mathrm{Sn}$, and $\mathrm{Kr}$ ions, or ex situ, using a CARY 2300 spectrophotometer at room temperature (Département de Physique des Matériaux) for the cluster and the U beams. Transmission electron microscopy observations were performed using a $200 \mathrm{keV}$ JEOL CX electron microscope.

\section{RESULTS}

\section{A. Optical-absorption measurements}

The optical-absorption spectrum of small metallic particles embedded in an insulating medium is characterized by a broad absorption band associated to the surface plasma resonance of free electrons in the precipitates. This absorption band can be described by the Mie theory, ${ }^{10-12}$ which relates the total extinction coefficient $\gamma$ (i.e., absorption plus scattering) due to a dilute concentration of metallic spheres of radius $R$ to their complex dielectric constant $\epsilon=\epsilon_{1}-i \epsilon_{2}$. In the free path model, ${ }^{10,13}$ the complex dielectric constant of metallic particles is expressed as the sum of Drude terms $A$ and interband terms $B$ :

$$
\begin{aligned}
& \epsilon_{1}=A_{1}(\omega)+B_{1}(\omega)=\epsilon_{0}-\frac{\nu_{p}^{2}}{\nu^{2}+\nu_{0}^{2}}+B_{1}(\omega), \\
& \epsilon_{2}=A_{2}(\omega)+B_{2}(\omega)=\frac{\nu_{0} \nu_{p}^{2}}{\nu\left(\nu^{2}+\nu_{0}^{2}\right)}+B_{2}(\omega),
\end{aligned}
$$

where $\omega, \nu, \nu_{p}$, and $\nu_{0}$ are, respectively, the light pulsation and frequency, the metal bulk plasma frequency, and the collision frequency of the free electrons within the metallic particles. The interband terms $B_{1}$ and $B_{2}$ were evaluated for bulk metal ${ }^{14}$ and used for the small particles without any modification.

When the particle radius $R$ is comparable or smaller than the bulk mean free path $l_{\infty}$, the scattering of the free electrons by the precipitate surface cannot be neglected and the effective mean free path $l$ of the free electrons is given by $^{10,12,15}$

$$
\frac{1}{l}=\frac{1}{l_{\infty}}+\frac{1}{R} .
$$

The collision frequency $\nu_{0}$ is then a function of the precipitate radius and can be expressed as

$$
\nu_{0}=\nu_{0}(R)=\nu_{0}(\text { bulk })+\frac{v_{F}}{R},
$$

where $\nu_{0}$ (bulk) is the bulk collision frequency and $v_{F}$ is the Fermi velocity in the metal.

For very small metallic particles, the wavelength $\lambda_{m}$ of the maximum of the surface plasmon band can be approximated by the Doyle formula

$$
\lambda_{m}=\lambda_{p} \sqrt{1+2 n_{0}^{2}},
$$

where $\lambda_{p}$ is the bulk plasmon wavelength of the metal and $n_{0}$ the refractive index of the insulating matrix. For $\mathrm{Na}$ nanoprecipitates in a $\mathrm{MgO}$ matrix, the maximum $\lambda_{m}$ of this absorption band lies around $550 \mathrm{~nm}$. The half width of the surface plasmon band decreases when the mean free path of the electrons in the metallic particles increases, due to a change of $R$ or $l_{\infty}$, and its area is proportional to the number of precipitated metal atoms.

The analysis of the experimental optical-absorption spectra was performed as follows. The complex dielectric constant $\epsilon$ of the metallic particles was calculated with Eqs. (1)-(4). The total extinction coefficient $\gamma$ could then be calculated from $\epsilon$ for all wavelengths. The parameters of the calculation (i.e., the concentration of metallic particles, $R$ and $\nu_{p}$ ) were chosen so that $\gamma$ would fit the experimental results.

As an example, Fig. 1 (curve a) presents the in situ optical-absorption spectrum obtained for a $\mathrm{MgO}$ crystal containing Na nanoprecipitates; only the plasma absorption band of the metallic precipitates is observed. The small band located around $375 \mathrm{~nm}$ is a satellite band. The mean precipitate size deduced from the half width of the absorption band is $9.6 \mathrm{~nm} \pm 0.2 \mathrm{~nm}$. Under irradiation with $\mathrm{Pb}$ ions at $944 \mathrm{MeV}$, the amplitude of the precipitate absorption band decreases, indicating a reduction in the number of precipitated sodium atoms. A broadening of the $\mathrm{Na}$ absorption band is observed with the irradiation fluence. It can be ascribed to a decrease of the mean free path of the electrons in the precipitates or to a modification of the size distribution. The same evolution is observed for irradiation temperatures of 17 and $300 \mathrm{~K}$. No influence of the precipitate size in the 9-14 nm range could be detected during irradiation with Sn ions. Table II gives, for each bombarding ion or cluster, the effective radius deduced from the optical-absorption spectrum before bombardment and after the final irradiating fluence.

$\mathrm{C}_{2}$ irradiations were performed on a $\mathrm{MgO}-\mathrm{Na}$ sample up to a fluence of $2 \times 10^{13} \mathrm{~cm}^{-2}$ : no modification of the absorption band of the precipitates could be detected. The opticalabsorption spectra of $\mathrm{MgO}-\mathrm{Na}$ samples before and after irra- 


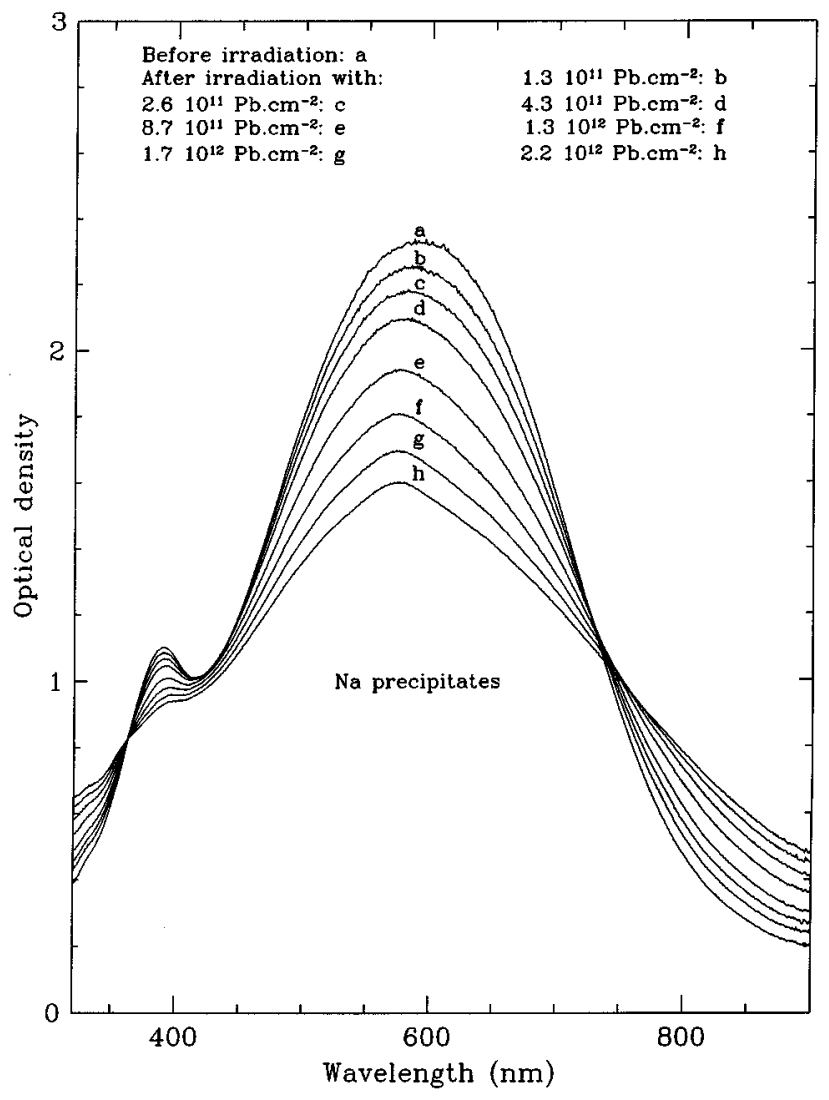

FIG. 1. Optical-absorption spectra of a $\mathrm{MgO}$ crystal containing $\mathrm{Na}$ precipitates irradiated with $\mathrm{Pb}$ at $38 \mathrm{keV} / \mathrm{nm}$.

diation with $\mathrm{C}_{60}$ clusters at $62 \mathrm{keV} / \mathrm{nm}$ are presented in Fig. 2 . The evolution is the same as for the irradiations with swift monoatomic ions (decrease of the plasma absorption band with fluence), except that no significant broadening of the metallic precipitate band was measured.

\section{B. Electron microscopy observations}

In-plane views for electron microscopy have been realized on a MgO-Na sample irradiated with $\mathrm{Sn}$ at $19 \mathrm{keV} / \mathrm{nm}$. The corresponding diffraction pattern is presented in Fig. 3 . The $\mathrm{MgO}$ matrix is a face-centered-cubic lattice with a lattice parameter $0.421 \mathrm{~nm}$. The structure of the sodium precipitates is body-centered-cubic, with a lattice parameter of $0.429 \mathrm{~nm}$. The precipitates are oriented with respect to the $\mathrm{MgO}$ matrix

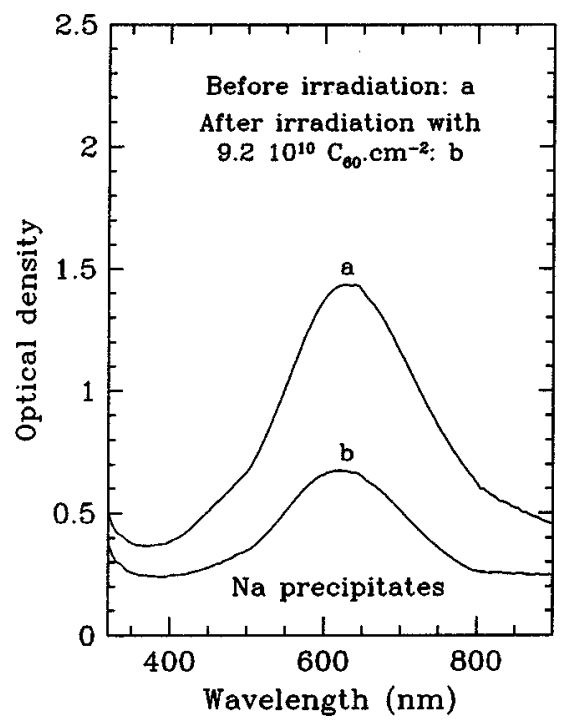

FIG. 2. Optical-absorption spectra of a $\mathrm{MgO}$ crystal containing $\mathrm{Na}$ precipitates irradiated with $\mathrm{C}_{60}$ clusters at $60 \mathrm{keV} / \mathrm{nm}$.

$$
\text { (001) } \mathrm{Na} \|(001) \mathrm{MgO} \text { and }[100] \mathrm{Na} \|[100] \mathrm{MgO}
$$

as previously observed by Treilleux. ${ }^{16}$

Figures 4(a) and 4(b), show dark-field images obtained with the (110) sodium reflection. A decrease of the precipitate number is observed after irradiation with $9.1 \times 10^{13}$ $\mathrm{Sn} \mathrm{cm}^{-2}$. The size distribution of the precipitates before and after irradiation, displayed in Fig. 5, does not show any significant modification of the mean size of the precipitates and of the standard deviation of the distribution. These samples were stable under the electron beam of the microscope, showing again that the $\mathrm{MgO}-\mathrm{Na}$ system is very resistant to irradiation with weak ionizing particles.

\section{DISCUSSION}

\section{A. Damage creation}

Optical-absorption measurements as well as electron microscopy observations show that the concentration of sodium precipitates in the matrix decreases during irradiation with either swift heavy monoatomic ions or with clusters. Before irradiation, the mean free path of the electrons in metallic precipitates deduced from optical-absorption measurements (see Table II) is in good agreement with the sodium particle

TABLE II. Effective precipitate radii $R$ deduced from optical-absorption measurements.

\begin{tabular}{lcccc}
\hline \hline $\begin{array}{l}\text { Incident } \\
\text { ion }\end{array}$ & $\begin{array}{c}\text { Radius before } \\
\text { irradiation }(\mathrm{nm})\end{array}$ & $\begin{array}{c}\text { Final irradiation } \\
\text { fluence } D\left(\mathrm{~cm}^{-2}\right)\end{array}$ & $\begin{array}{c}\text { Radius after final } \\
\text { irradiation }(\mathrm{nm})\end{array}$ & Remarks \\
\hline $\mathrm{U}$ & 3.5 & $8 \times 10^{12}$ & 2.8 & Irradiation temperature $300 \mathrm{~K}$ \\
$\mathrm{~Pb}$ & 4.8 & $2.2 \times 10^{12}$ & 3.3 & Irradiation temperature $17 \mathrm{~K}$ \\
$\mathrm{~Pb}$ & 5.0 & $8.7 \times 10^{11}$ & 4.2 & \\
$\mathrm{Sn}$ & 6.9 & $9.1 \times 10^{13}$ & 4.9 & \\
$\mathrm{Sn}$ & 5.0 & $7.6 \times 10^{13}$ & 3.8 & \\
$\mathrm{Kr}$ & 5.8 & $1.75 \times 10^{14}$ & 5.6 & \\
$\mathrm{C}_{2}$ & 3.4 & $2 \times 10^{13}$ & 3.5 & $\mathrm{C}_{60}$ energy: $18 \mathrm{MeV}$ \\
$\mathrm{C}_{60}$ & 5.6 & $2.1 \times 10^{11}$ & 5.4 & $\mathrm{C}_{60}$ energy: $23 \mathrm{MeV}$ \\
$\mathrm{C}_{60}$ & 6.9 & $9.1 \times 10^{10}$ & 7.1 & \\
\hline \hline
\end{tabular}




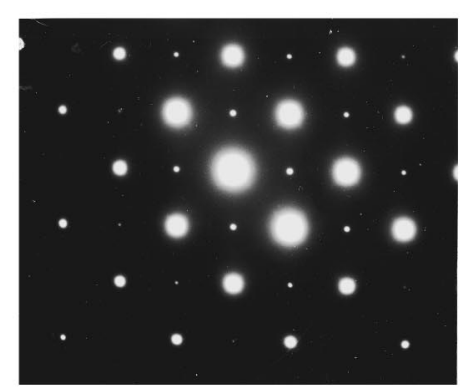

size deduced from electron microscopy, indicating that the free electrons of the precipitates are only scattered by the boundaries of the sodium particles.

The comparison of optical-absorption spectra and electron microscopy measurements is a little more complicated after irradiation with energetic monoatomic ions. The opticalabsorption spectra show a broadening of the metallic sodium absorption band. Such an evolution is usually ascribed to a decrease of the mean size of the precipitates. However, electron microscopy observations give no evidence of any significant modification of the mean size of sodium particles. We must then consider that irradiation introduces an extra limitation to the mean free path $l$.

This extra limitation of the mean free path could originate from a strong modification of the interface between the metallic precipitates and their matrix. Interface effects have been proposed by Kreibig and Genzel ${ }^{17}$ to explain differences observed in the plasma band widths of $\mathrm{Ag}$ particles produced in hydrosols by different preparation methods. When the interface between the metallic precipitates and the dielectric matrix is modified, the electron density profile normal to the particle surface changes, and it was shown ${ }^{18}$ that the plasma bandwidth depends on this density profile. Indeed, the interface between our sodium precipitates and the $\mathrm{MgO}$ matrix is likely to undergo changes during the dissolution process which takes place under irradiation.

As another interesting assumption, we could consider that the mean free path $l$ is not only limited by the boundaries of the precipitates, but also by the presence of defects created during irradiation. In bulk metals, the existence of defects is known to reduce the electron mean free path; ${ }^{19} l$ would then be calculated by

$$
\frac{1}{l}=\frac{1}{l_{\infty}^{\prime}}+\frac{1}{R},
$$

where $l_{\infty}^{\prime}$ is the new bulk mean free path, taking into account the existence of defects. Then

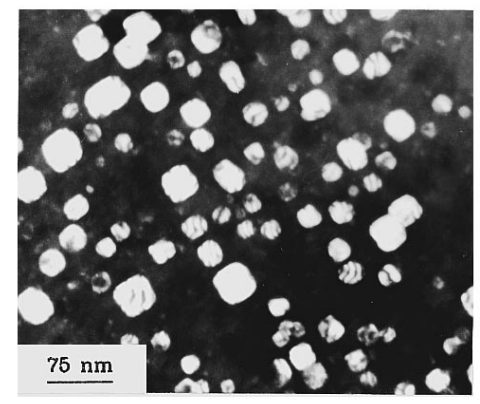

(a)

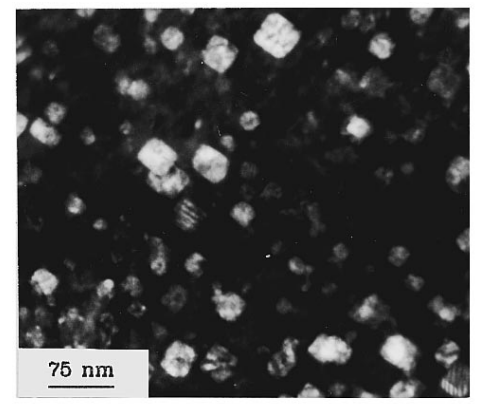

$$
\frac{1}{l_{\infty}^{\prime}}=\frac{1}{l_{\infty}}+\frac{1}{l_{d}}
$$

where $l_{d}$ is the mean free path due to the presence of defects.

Let us consider a metallic sodium body-centered-cubic lattice of parameter $a$. Each site is occupied by an atom or a defect, and $c$ is the atomic fraction of defects. As electrons are scattered only by defects, we could make the assumption that the mean distance between two defects is equal to $l_{d}$ and write

$$
l_{d}=\frac{(a / \sqrt[3]{2})}{c} .
$$

The atomic fraction of defects in the precipitates is then calculated with Eqs. (5)-(7), $R$ and $l$ being deduced from optical-absorption measurements, respectively, before and after irradiation. The variation of the defect atomic fraction with the irradiation fluence $\phi$ is displayed for various irradiation conditions in Fig. 6. This defect fraction is probably underestimated, as electrons may be scattered by defects with an efficiency lower than 1 . The real defect concentration would then be higher than the one deduced from this simple calculation. We can note that the irradiation temperature has no influence on the defect creation in $\mathrm{Na}$ and that the damage effect is strongly dependent on the electronic energy loss.

It is possible to define a damage cross section for the sodium precipitates by

$$
\sigma_{\mathrm{daNa}}=\left(\frac{d c}{d \phi}\right)_{\phi \rightarrow 0} .
$$

A rough estimate of $\sigma_{\mathrm{daNa}}$ can be derived for the samples which were subjected to in situ optical-absorption measurement, i.e.,
FIG. 4. Room-temperature dark-field electron microscopy observations of $\mathrm{Na}$ precipitates in $\mathrm{MgO}$ obtained with $\mathrm{Na}(110)$ reflection. (a) Before irradiation. (b) After irradiation with $9.1 \times 10^{13} \mathrm{Sn} \mathrm{cm}^{-2}$. 
a) Before irradiation

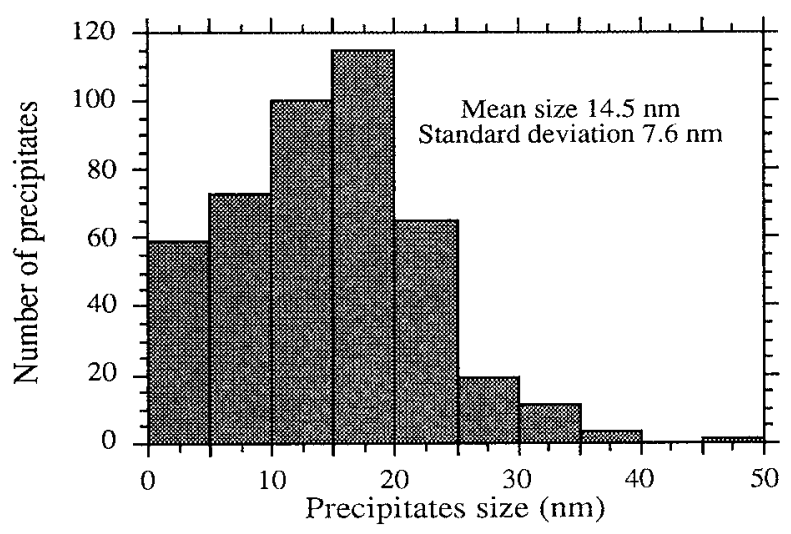

b) After irradiation

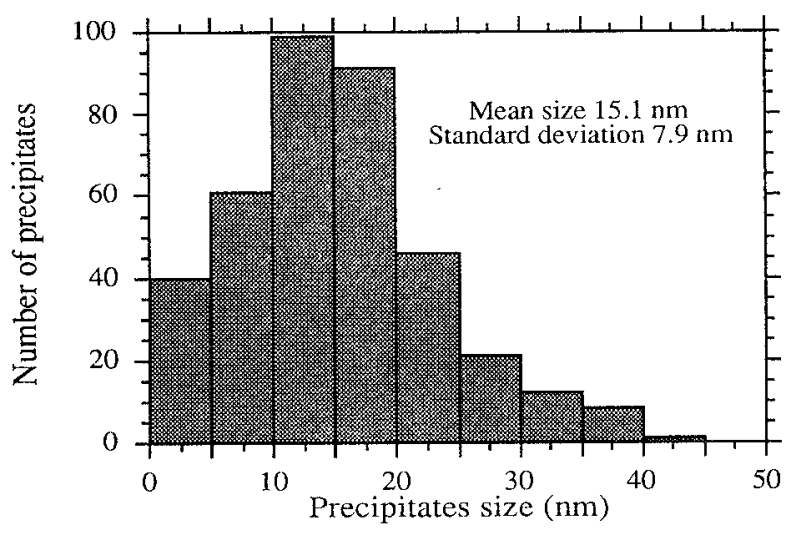

FIG. 5. Na precipitate size distributions. (a) Before irradiation. (b) After irradiation with $9.1 \times 10^{13} \mathrm{Sn} \mathrm{cm}^{-2}$.

$$
\begin{aligned}
& \sigma_{\mathrm{daNa}} \sim 1.4 \times 10^{-14} \mathrm{~cm}^{2} \text { for } \mathrm{Pb} 38 \mathrm{keV} / \mathrm{nm}, \\
& \sigma_{\mathrm{daNa}} \sim 4.0 \times 10^{-16} \mathrm{~cm}^{2} \text { for Sn } 19 \mathrm{keV} / \mathrm{nm}, \\
& \sigma_{\mathrm{daNa}} \sim 1.6 \times 10^{-17} \mathrm{~cm}^{2} \text { for } \mathrm{Kr} 11 \mathrm{keV} / \mathrm{nm} .
\end{aligned}
$$

One can note that the damage cross sections as well as the above calculated defect atomic fractions have sufficiently low values to be realistic. A metallic precipitate containing a few percent of defects remains metallic and should be detected by optical-absorption spectroscopy.

No significant damage effect of the cluster beams on sodium precipitates could be detected. This may be related to the fact that the range of secondary electrons induced by cluster irradiations is much shorter than it is in the case of swift monoatomic ion irradiations.

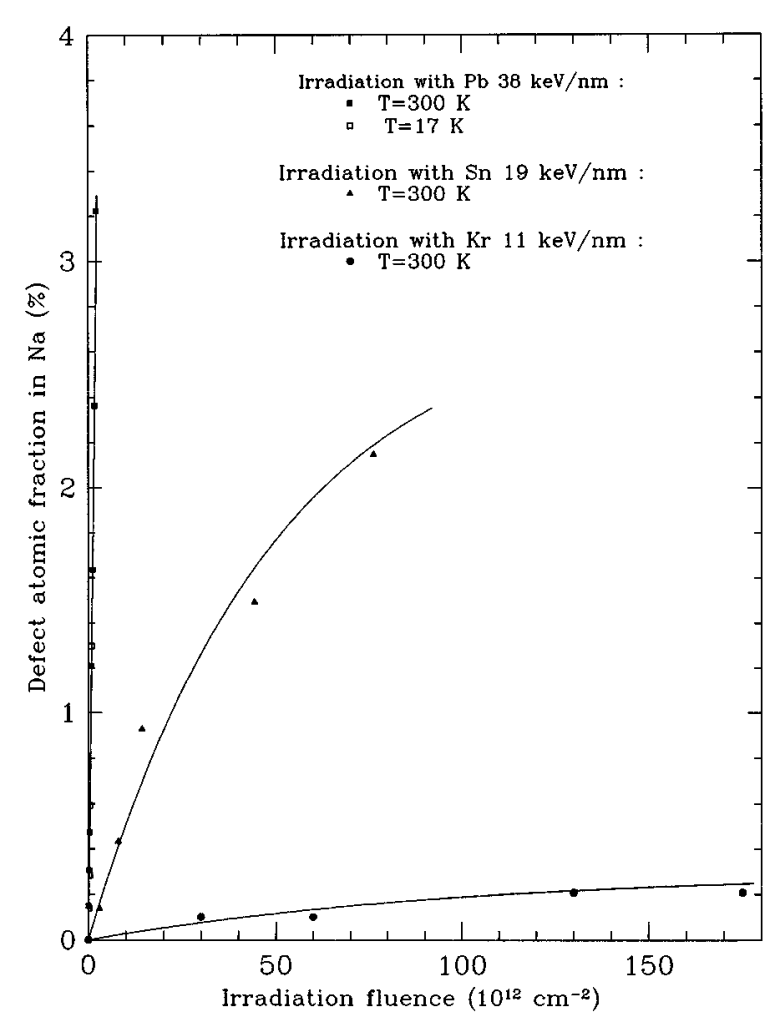

FIG. 6. Defect atomic fraction induced in Na precipitates by irradiation.

\section{B. Destruction of precipitates}

From optical-absorption measurements it is also possible to get information about the efficiency of precipitate destruction. The rate of precipitate destruction is defined by

$$
\tau=\frac{c_{0}-c}{c_{0}},
$$

where $c_{0}$ and $c$ are, respectively, the volumic fraction of $\mathrm{Na}$ atoms precipitated before and after irradiation. $\tau$ increases with the irradiation fluence $\phi$. When complete kinetics of precipitate disappearance are available, a destruction cross section $\sigma_{\mathrm{de}}$ can be calculated by

$$
\sigma_{\mathrm{de}}=\left(\frac{d \tau}{d \phi}\right)_{\phi \rightarrow 0} .
$$

If not, the destruction cross section can only be roughly estimated with $\sigma_{\mathrm{de}} \sim \tau / \phi$.

For swift monoatomic ions, this cross section lies between $2.6 \times 10^{-13} \mathrm{~cm}^{2}$ (for $\mathrm{Pb} 38 \mathrm{keV} / \mathrm{nm}$ ) and $3.4 \times 10^{-16} \mathrm{~cm}^{2}$ (for $\mathrm{Kr} 11 \mathrm{keV} / \mathrm{nm})$. Higher values were estimated for the cluster irradiations, up to $6 \times 10^{-12} \mathrm{~cm}^{2}$ for $62 \mathrm{keV} / \mathrm{nm} \mathrm{C}_{60}$ (see Table III).

TABLE III. Dissolution cross sections $\sigma_{e}$ for different bombarding ions.

\begin{tabular}{lcccccc}
\hline \hline & & & & & $\mathrm{C}_{60}$ & \\
Incident ion & $\mathrm{U}$ & $\mathrm{Pb}$ & $\mathrm{Sn}$ & $\mathrm{Kr}$ & $\begin{array}{c}\mathrm{C}_{60} \\
(18 \mathrm{MeV})\end{array}$ & $(23 \mathrm{MeV})$ \\
\hline $\begin{array}{l}\sigma_{e} \\
\left(\mathrm{~cm}^{2}\right)\end{array}$ & $2 \times 10^{-14}$ & $2.6 \times 10^{-13}$ & $5.5 \times 10^{-15}$ & $3.4 \times 10^{-16}$ & $5.6 \times 10^{-13}$ & $6.3 \times 10^{-12}$ \\
\hline \hline
\end{tabular}




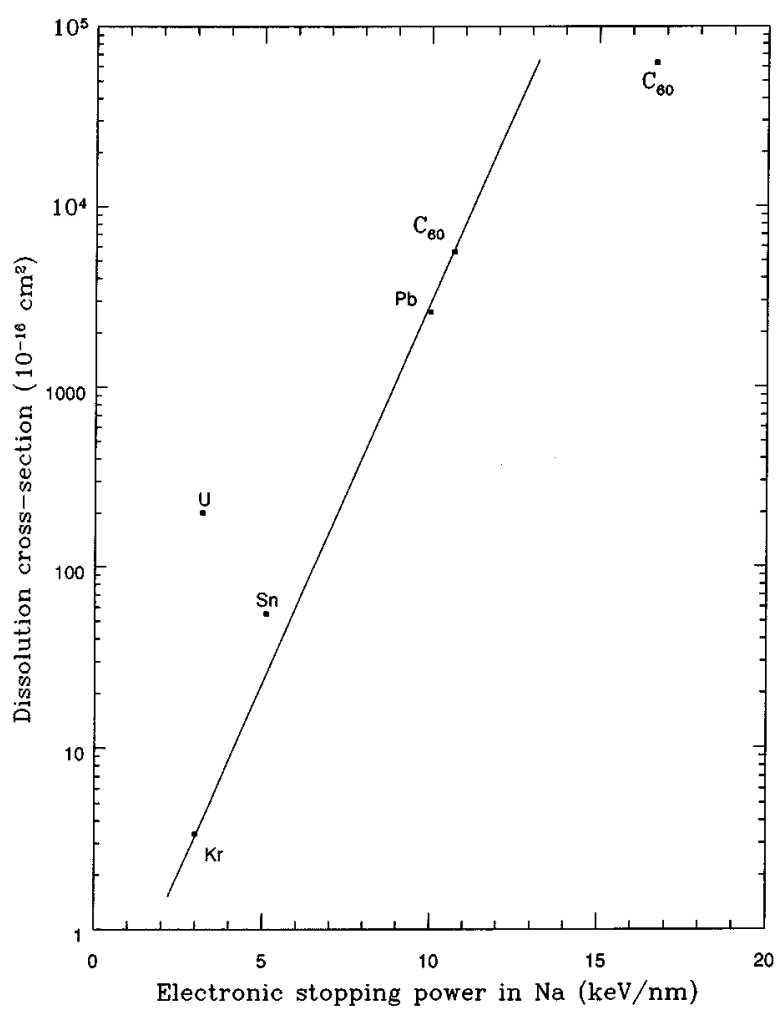

FIG. 7. Dissolution cross section of Na precipitates versus electronic stopping power.

$\mathrm{MgO}$ single crystals containing Na precipitates had been previously irradiated with low-energy monoatomic ions losing most of their energy by elastic collisions. Similar effects of disappearance of precipitates had been observed; the nuclear dissolution cross sections obtained in this case $\mathrm{e}^{16}$ ranged from $3.3 \times 10^{-17} \mathrm{~cm}^{2}$ and $4 \times 10^{-15} \mathrm{~cm}^{2}$. They were therefore of the same order of magnitude as the ones which were observed in this study during irradiation with highenergy monoatomic ions.

To decide whether the dissolution of Na precipitates obtained in our study (by irradiation with swift heavy ions and $\mathrm{C}_{60}$ clusters) should be ascribed to nuclear or electronic energy losses, TRIM calculations of the damage induced by elastic collisions were performed. The number of displaced atoms of sodium per incident ion was estimated between $2.2 \times 10^{-3}$ and $2.7 \times 10^{-5}$, depending on the irradiation conditions. Such low values cannot account for the disappearance of several percent of the precipitates, so we must conclude that the ionization processes play a dominant role in the dissolution of the sodium particles. Moreover, a rather good correlation is found between the destruction cross section of the precipitates and the electronic energy losses of the incident ions in the Na precipitates (displayed in Fig. 7). It can be seen that the dissolution cross section increases very rapidly with the value of the electronic energy loss and that it approximately follows an exponential relationship. The destruction cross sections obtained with cluster irradiations are then higher than the ones obtained with monoatomic ions.

The fact that $\mathrm{MgO}$ crystals containing alkali precipitates are modified by high densities of electronic excitations is confirmed by the experiments of Rankin et al. ${ }^{20}$ Small potassium metallic particles embedded in a $\mathrm{MgO}$ matrix were shown to be sensitive to pulsed-laser irradiation at a frequency near the absorption resonance of the alkali metal particles. One can also think of the experiments of Vollmer et $a l^{21}{ }^{21}$ They illuminated sodium particles deposited on a LiF surface with laser light and observed a nonthermal desorption of the Na clusters which is strongly dependent on the surface plasmon excitation. However, the evolution under irradiation of $\mathrm{Na}$ nanoprecipitates embedded in a $\mathrm{MgO}$ matrix should be different from the evolution of free sodium clusters, because the magnesium oxide prevents the evaporation of $\mathrm{Na}$ atoms at the surface of the precipitates.

Finally, let us recall that $\mathrm{C}_{2}$ irradiations on $\mathrm{MgO}-\mathrm{Na}$ samples did not lead to any significant dissolution of the sodium precipitates. The energy per atom of carbon $(300$ $\mathrm{keV})$ and the fluence of $\mathrm{C}$ atoms $\left(2 \times 10^{13} \mathrm{~cm}^{-2}\right)$ in this $\mathrm{C}_{2}$ experiment were similar to the ones used during $\mathrm{C}_{60}$ irradiations. This indicates that the nuclear cascades induced by $\mathrm{C}_{2}$ atoms (or decorrelated $\mathrm{C}$ atoms) are not powerful enough to destroy the sodium precipitates. The electronic energy losses of $\mathrm{C}_{2}$ molecules are neither sufficiently large to dissolve the $\mathrm{Na}$ particles, unlike the $\mathrm{C}_{60}$ electronic energy losses. Indeed, even if $\mathrm{C}_{60}$ and $\mathrm{C}_{2}$ clusters have the same velocity, the local energy deposited by these aggregates is very different. It is known that, when a cluster enters a solid, it breaks into several fragments. However, as long as these fragments keep a close spatial correlation, the local electronic energy deposited by $\mathrm{C}_{60}$ clusters should be at least 30 times higher than the one deposited by $\mathrm{C}_{2}$ molecules. This is sufficient to explain the differences observed in the dissolution cross sections with $\mathrm{C}_{60}$ and $\mathrm{C}_{2}$ molecules.

The cross section $\sigma_{\mathrm{de}}$, which was roughly estimated in the case of $U$ irradiation, presents a somewhat different behavior. Its value is much higher than the one which was obtained with the same electronic energy loss for $\mathrm{Kr}$ irradiations. It can be attributed to a precipitate size effect, as sodium particles irradiated with $U$ ions were smaller (7 $\mathrm{nm}$ in size) than the ones irradiated with $\mathrm{Kr}$ ions $(11.4 \mathrm{~nm})$. Such precipitate size effects were also observed by Treilleux et al. in the nuclear energy-loss regime. ${ }^{22}$

\section{Comparison with available models}

Ionization processes at high electronic stopping power have been shown to induce the dissolution of Na precipitates in their $\mathrm{MgO}$ matrix. However, the problem of the conversion of the energy transferred to electrons into lattice defects is still an open question. The main models which have been put forward to explain this conversion up to now are (i) the thermal spike, ${ }^{23}$ in which the energy of the electrons is transferred to the lattice via electron-phonon coupling; (ii) the Coulomb explosion model, ${ }^{24}$ in which the highly ionized matter located in the wake of the incident ion explodes due to electrostatic repulsion between charges.

\section{Coulomb explosion model}

In this model, the passage of the incident ion leads to the ionization of the atoms on its trajectory and then to the sudden creation of a space charge. In a metal, this space charge is rapidly screened by the free electrons. The atoms of the metal are subjected to an electric field and they acquire a certain quantity of kinetic energy. The key parameter char- 


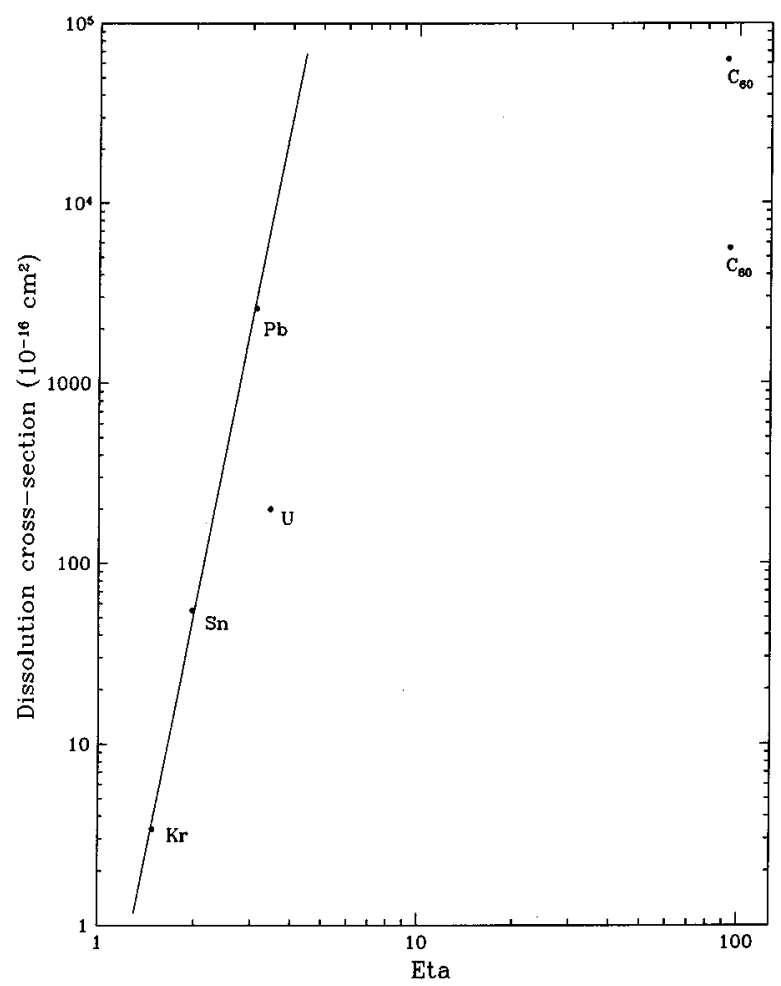

FIG. 8. Dissolution cross section of $\mathrm{Na}$ precipitates in $\mathrm{MgO}$ in the framework of the Coulomb explosion model.

acterizing the irradiation conditions is $\eta=Z_{1}^{*} v_{0} / v$, where $Z_{1}^{*}$ is the effective charge of the incident ion, $v$ its velocity, and $v_{0}$ is the Bohr velocity. It has been shown ${ }^{24}$ that the kinetic energy $E_{c}$ acquired by the atoms of the lattice is proportional to $\eta^{8}$.

The dissolution of sodium precipitates in the $\mathrm{MgO}$ matrix should be related to some extent to the kinetic energy acquired by the metallic atoms in the wake of the incident ion or cluster. With swift monoatomic ions, the effective charge can be calculated by the following relation: ${ }^{25,26}$

$$
Z_{1}^{*}=Z_{1}\left[1-\exp \left(\frac{-v}{v_{0} Z_{1}^{2 / 3}}\right)\right]
$$

For $\mathrm{C}_{60}$ ions, we can consider that the effective charge of the cluster is equal to the sum of the effective charges of all the atoms making up the cluster and use this relation.

The dissolution cross section $\sigma_{\mathrm{de}}$ (from Table III) has been plotted in Fig. 8 with the parameter $\eta$ on a $\log -\log$ scale. It can be deduced from this curve that $\sigma_{\mathrm{de}}$ is proportional to $\eta^{9 \pm 1}$ in the case of monoatomic ions, so it is in agreement with the Coulomb explosion model. However, cluster ions do not appear to follow such a law. The influence of the size of the precipitates is also difficult to include precisely in such a model.

\section{Thermal spike model}

In this model, the energy of secondary electrons produced by ionization is transferred to the lattice via electron-phonon coupling. A local rise of temperature appears, which is proportional to the electronic energy losses $(d E / d x)_{\mathrm{el}}$ of the bombarding ions. ${ }^{23}$ The most relevant parameter for damage

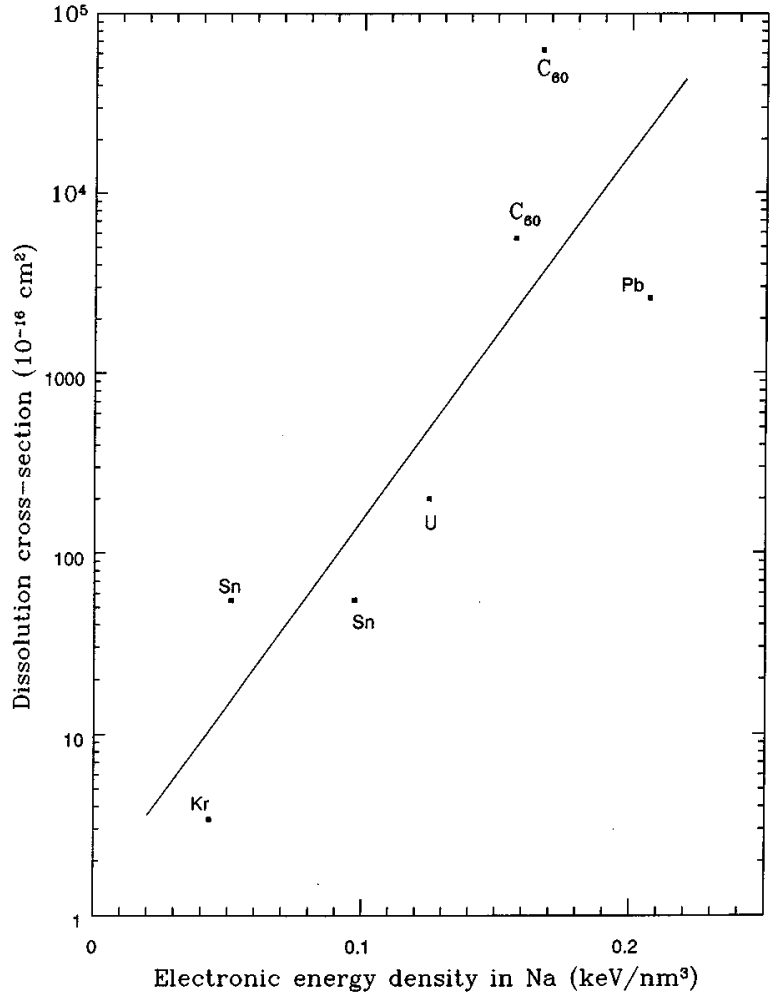

FIG. 9. Dissolution cross section of $\mathrm{Na}$ precipitates in $\mathrm{MgO}$ in the framework of the thermal spike model.

creation is the energy density deposited along the projectile track. ${ }^{27}$ Following this approach, we assumed that the energy lost by a projectile when passing through a precipitate of radius $R$ was confined within the precipitate and shared among all atoms of the precipitate. An energy density $D_{e}$ can then be derived from the electronic energy losses:

$$
D_{e}=\left(\frac{d E}{d x}\right)_{\mathrm{el}} \times q R \times\left(\frac{4}{3} \pi R^{3}\right)^{-1}
$$

The precipitate dissolution cross section $\sigma_{\mathrm{de}}$ (from Table III) is plotted versus $D_{e}$ in Fig. 9. The deviation of the $\mathrm{U}$ point, observed in Fig. 7, is no longer present in Fig. 9 because the energy density $D_{e}$ takes into account the smaller size of the precipitates. The scatter of the experimental points is quite important; however, one might have naively expected more scatter of the other points because of differences in their precipitate distributions. $D_{e}$ is about equal to 0.125 $\mathrm{keV} / \mathrm{nm}^{3}$ in the middle of the range covered. In this case, each atom of the precipitate gets about $5 \mathrm{eV}$, so that even if only a fraction of the deposited energy is retained, the $\mathrm{Na}$ atoms are ionized (ionization potential for $\mathrm{Na}: 5.2 \mathrm{eV}$ ) and the precipitates become very hot.

The time necessary for most ejected electrons to return to the projectile track is of the order of magnitude of $10^{-14} \mathrm{~s}$; this is much shorter than the time required for most $\delta$ ray electrons to get trapped in an insulator. ${ }^{28}$ So, after the passage of a projectile ion, the Na precipitate probably consists of a hot, neutral plasma. The cooling of the electrons is difficult, because the high band gap of $\mathrm{MgO}$ tends to retard the transfer of energy into the bulk of the insulator-although 
band bending at the surface of the precipitate may allow a region adjacent to the precipitate to be heated, too.

Unlike semiconductors, bulk magnesium oxide is a highly ionic insulating material whose amorphization has never been observed under irradiation with low-energy ions because

(i) irradiation defects are created in equal quantities in the $\mathrm{Mg}$ and $\mathrm{O}$ sublattices (the displacement energy is about the same for these two atoms ${ }^{29}$ );

(ii) perfect dislocation loops are created by elastic collisions ${ }^{30}$ they coexist with very localized vacancy defects. $^{29}$

Such localized defects do not induce significant density of states in the $\mathrm{MgO}$ band gap and do not facilitate the cooling of free electrons in the $\mathrm{Na}$ precipitates.

Considering the relatively large energies acquired by $\mathrm{Na}^{+}$ ions and their small ionic radius ${ }^{31}$ (about $0.3 \AA$ ), the $\mathrm{Na}^{+}$ ions are likely to diffuse outwards, leading to the precipitate destruction. Thus, the evolution of $\sigma_{\mathrm{de}}$ with the energy density $D_{e}$ may be approximated by a vapor-pressure-like relation. We fit the data in Fig. 9 with an equation of this form:

$$
\sigma_{\mathrm{de}}=\sigma_{0} e^{\Lambda D_{e}}
$$

and obtain $\sigma_{0} \sim 1.4 \AA^{2}$ and $\Lambda \sim 47 \mathrm{~nm}^{3} / \mathrm{keV}$ as fitting parameters. $\sigma_{0}$ is roughly comparable to the ionization cross section one might expect for an electron on $\mathrm{Na}$, i.e., the size of the neutral atom. The equivalent of a "latent heat of ionization" to be used is

$$
\Lambda^{-1}=\frac{I}{\bar{\nu}},
$$

where $\bar{\nu}$ is the atomic volume of $\mathrm{Na}$ and $I$ is its ionization potential. This derived value of $\Lambda$ yields $I \sim 1 \mathrm{eV}$, which is a correct order of magnitude for an ionization potential.
A better evaluation of the thermal spike model would include velocity effect calculations. Moreover, if one compares the dissolution cross section obtained during $62 \mathrm{keV} / \mathrm{nm} \mathrm{C}_{60}$ irradiations $\left(630 \mathrm{~nm}^{2}\right)$ to the area of a precipitate $\left(150 \mathrm{~nm}^{2}\right)$, one observes that the efficiency of dissolution is greater than 1. This indicates that a bombarding ion can destroy more than one precipitate at once. The influence of the $\mathrm{MgO}$ matrix has then to be taken into account in the energy density calculations.

\section{CONCLUSION}

In this work, we have shown that the ionization processes induced by irradiation with swift heavy ions or clusters can lead to the destruction of sodium precipitates embedded in a $\mathrm{MgO}$ matrix. Associated with the dissolution of metallic particles, we found that some lattice defects could be created in the metallic precipitates when they were subjected to highenergy monoatomic ion irradiation. As no effect of the temperature was observed in the range $17-300 \mathrm{~K}$, we can rule out thermally activated processes to explain these dissolution and damage phenomena.

The Coulomb explosion model might be proposed to understand the effect of high electronic stopping power on $\mathrm{MgO}-\mathrm{Na}$ systems. However, this model does not fit the observations from cluster beam irradiations. Following a thermal spike approach can allow us to describe the dissolution phenomena in a quite realistic way. In both cases, it would be necessary to include the influence of the precipitate size in the resolution process. One notes in this regard that the $U$ irradiation point is brought into agreement in the thermal spike model's dependence on precipitate size.
${ }^{1}$ J. P. Dupin, P. Thevenard, and M. Treilleux, Nucl. Instrum. Methods Phys. Res. Sect. B 19/20, 917 (1987).

${ }^{2}$ M. Treilleux and P. Thevenard, Nucl. Instrum. Methods Phys. Res. Sect. B 7/8, 601 (1985).

${ }^{3}$ M. Treilleux, P. Thevenard, M. O. Ruault, H. Bernas, and J. Chaumont, Nucl. Instrum. Methods Phys. Res. Sect. B 12, 375 (1985).

${ }^{4}$ D. M. Parkin, in Structure Property Relationships in Surface Modified Ceramics, Vol. 170 of Nato Advanced Study Institute, Series E: Applied Sciences, edited by C. J. McHargue, R. Kossowsky, and W. O. Hofer (Kluwer, Dordrecht, 1989), p. 47.

${ }^{5}$ A. Dunlop, D. Lesueur, P. Legrand, H. Dammak, and J. Dural, Nucl. Instrum. Methods Phys. Res. Sect. B 90, 330 (1994).

${ }^{6}$ S. Klaumunzer, M. D. Hou, and G. Schumacher, Phys. Rev. Lett. 57, 850 (1986)

${ }^{7}$ B. Canut, S. M. M. Ramos, P. Thevenard, N. Moncoffre, A. Benyagoub, G. Marest, A. Meftah, M. Toulemonde, and F. Studer, Nucl. Instrum. Methods Phys. Res. Sect. B 80/81, 1114 (1993).

${ }^{8}$ B. Canut, R. Brenier, A. Meftah, P. Moretti, S. Ould Salem, and S. M. M. Ramos, Nucl. Instrum. Methods Phys. Res. Sect. B 91, 312 (1994).

${ }^{9}$ K. Baudin, A. Brunelle, M. Chabot, S. Della Negra, J. Depauw,
D. Gardes, P. Hakansson, Y. Le Beyec, A. Billebaud, M. Fallavier, J. Remillieux, J. C. Poizat, and J. P. Thomas, Nucl. Instrum. Methods Phys. Res. Sect. B 94, 341 (1994).

${ }^{10}$ A. E. Hugues and S. C. Jain, Adv. Phys. 28(6), 717 (1979).

${ }^{11}$ M. Vollmer and U. Kreibig, in Nuclear Physics Concepts in the Study of Atomic Cluster Physics, edited by R. Schmidt et al. (Springer-Verlag, Berlin, 1992), p. 270.

${ }^{12}$ M. A. Smithard and M. Q. Tran, Helv. Phys. Acta 46, 869 (1974).

${ }^{13}$ U. Kreibig, J. Phys. F 4, 999 (1974).

${ }^{14}$ E. T. Arakawa, T. Inagaki, and M. W. Williams, Surf. Sci. 96, 248 (1980).

${ }^{15}$ D. M. Mann and H. P. Broida, J. Appl. Phys. 44(11), 4950 (1973).

${ }^{16}$ M. Treilleux, Ph.D. thesis, University of Lyon, 1982.

${ }^{17}$ U. Kreibig and L. Genzel, Surf. Sci. 156, 678 (1985).

${ }^{18}$ W. Ekardt, Phys. Rev. B 29, 1558 (1984).

${ }^{19}$ C. Kittel, in Physique de l'Etat Solide, edited by Dunod Université (Bordas, Paris, 1983), p. 168.

${ }^{20}$ J. Rankin, P. Thevenard, L. J. Romana, L. A. Boatner, C. W. White, C. J. McHargue, and L. L. Horton, Surf. Coat. Technol. 51, 471 (1992).

${ }^{21}$ M. Vollmer, R. Weidenauer, W. Hoheisel, U. Schulte, and F. 
Träger, Phys. Rev. B 40, 12509 (1989).

${ }^{22}$ M. Treilleux, J. P. Dupin, G. Fuchs, and P. Thevenard, Nucl. Instrum. Methods Phys. Res. Sect. B 19/20, 713 (1987).

${ }^{23}$ M. Toulemonde, E. Paumier, and C. Dufour, Radiat. Eff. Defects Solids 126, 201 (1993).

${ }^{24}$ D. Lesueur and A. Dunlop, Radiat. Eff. Defects Solids 126, 163 (1993).

${ }^{25}$ E. Balanzat and S. Bouffard, Solid State Phenomena 30/31, 7 (1993).

${ }^{26}$ M. Salehpour, D. L. Fishel, and J. E. Hunt, Phys. Rev. B 38, 12320 (1988).

${ }^{27}$ A. Meftah, F. Brisard, J. M. Constantini, M. Hage-Ali, J. P. Sto- quert, F. Studer, and M. Toulemonde, Phys. Rev. B 48, 920 (1993).

${ }^{28}$ R. H. Ritchie and C. Clausen, Nucl. Instrum. Methods Phys. Res. 198, 133 (1982).

${ }^{29} \mathrm{P}$. Thevenard, in Structure and Property Relations in Ion Beam Surface Modified Ceramics-Theory and Practice, edited by C. J. McHargue (Kluwer, Dordrecht, 1989), p. 1.

${ }^{30}$ E. Friedland, Nucl. Instrum. Methods Phys. Res. Sect. B 80/81, 128 (1993).

${ }^{31}$ J. C. Slater, in Quantum Theory of Atomic Structures (McGrawHill, New York, 1960), p. 210. 